\title{
SOBRE O PROCESSO DE FORMAÇÃO DO CIDADÃO ${ }^{1}$
}

\author{
Helena Esser dos Reis*
}

\begin{abstract}
RESUMO
Desde a aurora da modernidade, tornar-se cidadão, longe de ser algo natural ou espontâneo, exige esforço, na medida em que exige a cada um ultrapassar sua própria suficiência e independência. Em vista disto, Rousseau chega a afirmar a necessidade de transformar a natureza humana a fim de dotar cada indivíduo - que é um todo perfeito e solitário - da capacidade de coletivizar-se, de integrar-se a um corpo coletivo como parte inseparável. A dificuldade do projeto, ou do processo de formação do cidadão, reside em que tal exigência não se impõe espontaneamente aos indivíduos, embora seja condição necessária para o estabelecimento de uma relação harmônica entre cada um e o corpo coletivo. Discutir a tensão existente entre indivíduo e cidadão, investigando o esforço empreendido pelo legislador e por cada homem será o objeto deste artigo.
\end{abstract}

Palavras-chave: Filosofia. Política. Cidadão. Individual.

\begin{abstract}
Since the dawn of modernity, becoming a citizen, far from being something natural or spontaneous, has required effort, to the extent that it requires that each one overcomes his own self sufficiency and independence. In light of this, Rousseau comes to affirm the need to transform human nature so as to endow each individual, who is a perfect and solitary whole, with the capacity for collectivity, of integrating himself to a collective body as an inseparable part. The difficulty of the project, or of the educational process for becoming a citizen, resides in the fact that such a requirement is not imposed spontaneously on individuals, although it is a necessary condition for the establishment of a harmonious relationship between
\end{abstract}

\footnotetext{
* Doutorado em Filosofia pela Universidade de São Paulo (USP). Professora Adjunto do Departamento de Filosofia da Universidade Federal de Goiás (UFG). E-mail: helenaesser@ uol.com.br

1 A primeira versão deste texto sob o título "O esforço de tornar-se cidadão" foi apresentada no Colóquio Internacional Religião e Política em Rousseau: em torno das Cartas Escritas da Montanha, realizado na PUC/SP, de 11 a 13 de setembro de 2006.
} 
each individual and the collective body. Discussing the tension existing between individual and citizen, investigating the effort undertaken by the legislator and by each individual will be the object of this article.

Keywords: Rousseau. Philosophy. Politics. Citizen. Individual.

\section{Introdução}

Pensar o exercício da cidadania em companhia de Rousseau é uma tarefa estimulante, na medida em que seus textos nos reportam ao compromisso compartilhado por todos os membros do corpo político com o bem comum, como condição fundamental para o pleno desenvolvimento da liberdade humana. Entretanto, fazer-se cidadão, longe de ser algo natural ou espontâneo, exige esforço, na medida em que exige de cada indivíduo o ultrapassamento de sua condição natural caracterizada pela capacidade de bastar-se a si mesmo de modo independente dos demais. Analisando a tensão existente entre indivíduo e cidadão, e investigando o esforço empreendido pelo legislador e por cada um dos membros do corpo coletivo, o problema que nos interessa discutir aqui diz respeito ao processo de formação do cidadão, ou seja, de transformação de cada um, que "por si mesmo é um todo perfeito e solitário, em parte de um todo maior” (ROUSSEAU, 1978, L. II, cap. 7, p. 57).

\section{Da necessidade de prolongar o instante feliz}

Fazer parte de uma comunidade exige que cada indivíduo, em primeiro lugar, coloque-se em comum por meio da completa alienação de si mesmo ao corpo coletivo. Este primeiro ato, ou pacto fundante do estado civil, é caracterizado por Rousseau como "instante feliz" e tem a prerrogativa de arrancar - para sempre - o homem do seu estado de natureza e fazer com que este "animal estúpido e limitado", por meio da liberdade civil e moral, possa se tornar "um ser inteligente e um homem" (ROUSSEAU, 1978. L. I, cap. 8, p. 36).

É interessante observar a rapidez do processo. Ainda que o pacto se dê no plano do dever-ser e não no plano da história, é surpreendente que 
a passagem do estado de natureza para a o Estado Civil, por intermédio do pacto de associação, produza

imediatamente $^{2} \ldots$ em lugar da pessoa particular de cada contratante, um corpo moral e coletivo, composto de tantos membros quantos são os votos da assembléia, que, por esse mesmo ato, ganha sua unidade, seu eu comum, sua vida e sua vontade (ROUSSEAU, 1978. L. I, cap. 6, p. 33).

A descrição desta passagem como algo imediato ou como um instante restringe-se ao pacto ele mesmo. $\mathrm{O}$ ato de associação é apenas o momento de criação do corpo coletivo. Entretanto, ainda que este seja um instante feliz, Rousseau claramente percebe a insuficiência do instante, pois apesar da felicidade momentânea, o ato nada determina acerca da conservação deste corpo recém nascido: "o ato primitivo, pelo qual esse corpo de forma e se une, nada determina ainda daquilo que deverá fazer para conservar-se" (ROUSSEAU, 1978. L. II, cap 6, p. 53).

A conservação do corpo coletivo exige prolongar no tempo o propósito do pacto tornando durável, na memória e no coração de cada um dos membros do corpo coletivo, o compromisso com o bem comum. Partindo do suposto rousseauísta, que "o princípio da vida política reside na autoridade soberana” (ROUSSEAU, 1978. L. III, cap. 11, p. 102), devemos convir que o próprio instante feliz cria a possibilidade da sua continuidade, posto que o pacto não apenas congrega os indivíduos, mas cria um novo ser - diferente daqueles que o constituem e superior a cada um enquanto indivíduo - cuja vontade "é sempre certa e tende sempre à utilidade pública” (ROUSSEAU, 1978. L. II, cap. 3, p. 46).

A vontade geral é, portanto, o instrumento fundamental para a preservação do corpo político, visto que tende permanentemente ao próprio bem, ou seja, à conservação do corpo. Entretanto, ainda que Rousseau deduza as características da vontade geral do pacto de associação baseado na cláusula de alienação total, em momento algum ele considera que a tensão entre a vontade do corpo e a vontade de cada um tenha sido equacionada.

2 Grifo meu. 
Pelo contrário, Rousseau considera a existência de vontades particulares e, portanto, em tensão com a vontade geral, não apenas nos indivíduos eles mesmos, mas também em agrupamentos de indivíduos, tais como facções, representantes e até mesmo no governo. A compreensão desta tensão inerente aos corpos coletivos o leva a afirmar que "o corpo político, assim como o corpo do homem, começa a morrer desde o nascimento e traz em si mesmo as causas de sua destruição" (ROUSSEAU, 1978. L. III, cap. 11, p. 102).

É possível minimizarmos a tensão existente entre o coletivo e o privado diferenciando o objeto da vontade geral e da vontade particular. Se a primeira é, em cada indivíduo, "um ato puro de entendimento que raciocina no silêncio das paixões sobre o que o homem pode exigir de seu semelhante, e sobre o que o seu semelhante está no direito de exigir dele" (ROUSSEAU, 1964, p. 286), caracterizando-se pela reciprocidade e pela conveniência comum; a segunda, a vontade particular, não é mais do que a vontade de cada um, de modo que é própria de um ou de um grupo e está voltada para o interesse do indivíduo ou do grupo. Uma põe em evidência o que é comum, a outra o privado.

Se buscarmos eliminar a tensão entre a vontade geral e a vontade particular apenas pela distinção de seus objetos, a tensão tende a reaparecer sempre quando o indivíduo mantém-se, já no Estado Civil, preso à sua existência individual e considera "o que deve a causa comum como uma contribuição gratuita", de modo a querer "desfrutar dos direitos do cidadão sem querer desempenhar os deveres de súdito" (ROUSSEAU, 1978. L. I, cap. 7, p. 35-36). Neste caso, quando a vontade privada invade o espaço público desestabilizando a vontade geral, a tensão entre ambas se torna problemática.

Contudo, é preciso cautela, não se trata de extirpar a individualidade ou a vida privada dos membros do corpo coletivo. Na explicação mesma que Rousseau nos oferece acerca da vontade geral, em momento algum ele nega que quem enuncia a vontade geral seja cada um dos membros do corpo coletivo; nem tampouco ele afirma que estes cidadãos não possam ter vontades particulares. A existência individual ou particular de cada um com seus próprios interesses e vontades, não é o problema. Problema é o modo como cada um destes indivíduos - membros do corpo político - ouvem o próprio interesse e deliberam acerca do bem comum. A dificuldade está em fazer com que cada 
cidadão possa deliberar sempre "de acordo consigo mesmo" (ROUSSEAU, 1978. L. II, cap. 3, p. 47), mas não em vista de si mesmo.

Se a vontade geral era, como vimos, o instrumento fundamental para a manutenção do corpo político, compreendemos agora que ela não existe por si mesma. À diferença do corpo natural dotado espontaneamente de instintos que fazem qualquer animal buscar inequivocamente a própria sobrevivência, o corpo político, enquanto corpo artificial, apenas artificialmente mantém a si mesmo. A conservação do corpo político, "obra de arte" (ROUSSEAU, 1978. L. III, cap. 11, p. 102) humana, não é espontânea; nada determina à priori a conservação do corpo artificial. Ainda que por meio do pacto os homens constituam um novo ser, dotado de vontade própria, que, por si mesmo, tende permanentemente ao próprio bem, ou seja, à utilidade pública, nem sempre o povo encontra o bem que quer, pois nem sempre as deliberações deste corpo são tão certas quanto a sua vontade.

\section{Entre a vontade e a deliberação: a importância do legislador}

No capítulo VI do Livro II do Contrato Social, Rousseau afirma que apesar do povo querer sempre o próprio bem, nem sempre é capaz de encontrá-lo. Para livrar-se da acusação de paradoxal, explica: "a vontade geral é sempre certa, mas o julgamento que a orienta nem sempre é esclarecido" (ROUSSEAU, 1978. L. II, cap. 6, p. 56). A dificuldade de deliberação não decorre de uma falha no querer o bem do corpo, mas na capacidade de julgar acertadamente. O problema que precisamos enfrentar é, então, como realizar algo para o qual não temos, de antemão, as condições exigidas? Ou ainda: como dar durabilidade à associação política se o julgamento que orienta a vontade geral nem sempre é esclarecido?

Neste contexto, não há quem possa ser indiferente acerca da figura do legislador apresentada logo após, no capítulo VII do Livro II do Contrato Social. Sua tarefa não é apenas árdua, mas desmedida. O legislador parece assumir a tarefa de um demiurgo capaz de moldar os homens substituindo sua natureza originária, marcada pela independência e pela suficiência, por outra que o torne parte inequívoca de um todo do qual recebe sua vida e seu ser. Rousseau reforça ainda mais esta ideia de desmedida quando 
afirma: "seria preciso deuses para dar leis aos homens" (ROUSSEAU, 1978. L. II, cap. 7, p. 56). Porém, a própria forma verbal seria preciso3, usada por Rousseau, revela que a condição solicitada não é uma condição de fato. Ora, é preciso ter claro, Rousseau não está aprontando nenhuma armadilha para os seus leitores. Com tal caracterização do legislador e de sua tarefa, ele está, ao mesmo tempo, ressaltando sua importância e advertindo acerca de sua dificuldade. Pois bem, precisamos então enfrentar a pergunta: como orientar o julgamento do corpo político? Como realizar a transformação do indivíduo em cidadão? Ou ainda, como prolongar no tempo o propósito dos homens naquele instante feliz em que se associaram dando origem a um corpo coletivo?

Se, no Contrato Social, a transformação da natureza humana parece ser um pressuposto para a realização da vida política, em Considerações sobre o Governo da Polônia e Projeto de Constituição para a Córsega, a formação do cidadão acontece a cada momento da vida coletiva. Nestas obras, torna-se evidente a necessidade de dar continuidade à tarefa instituição do corpo político, posto que o instante feliz do pacto não é suficiente para outorgar ao indivíduo uma nova natureza. Importa, portanto, ao longo do tempo, tornar presente, aos membros do corpo político, o seu compromisso inicial com o bem comum. Eis porque, ainda no capítulo VII do L. II do Contrato Social, Rousseau esclarece o quanto é longa a tarefa do legislador, visto que afirma ser necessário trabalhar durante "um século" (ROUSSEAU, 1978. L. II, cap. 7, p. 56).

Um século de trabalho é um tempo bastante longo para um homem, o que nos leva a considerar que Rousseau - a despeito dos exemplos que apresenta - não pretende efetivamente que a tarefa seja realizada conclusivamente por apenas um homem. Do mesmo modo que não se trata de depositar nas mãos dos deuses a tarefa do legislador, tampouco trata-se de depositá-la nas mãos de um único homem. Mais uma vez, nomeando alguns poucos e importantes legisladores da história, Rousseau quer chamar atenção para a excelência da tarefa e daqueles que a cumprem.

Não se trata, portanto, de dotar o legislador de uma tarefa inalcançável alijando os indivíduos do esforço de tornarem-se cidadãos. A condição de cidadão exige agir como cidadão - esta é a única maneira de

3 Em francês: faudrait, conditionnel présent. 
"tornar o homem verdadeiramente senhor de si mesmo, porque o impulso do puro apetite é escravidão, e a obediência à lei que nós mesmos nos prescrevemos é liberdade" (ROUSSEAU, 1978. L. I, cap. 8, p. 37). Afastar os homens da tarefa inalienável de autodeterminação, seja na condição de indivíduo, seja na condição de cidadão, equivale a invalidar o projeto político rousseauísta.

Aprendemos com o Emílio que não é possível pensar o processo educacional sem que as duas partes - professor e aluno, legislador e cidadãos - estejam igual e livremente comprometidas com o processo. O esforço de fazer do indivíduo um cidadão deve ser compreendido, portanto, como um esforço compartilhado e permanente que a todos dignifica. A tarefa do legislador não se cumpre à revelia dos cidadãos; costumes cívicos não serão gravados no coração dos cidadãos sem que eles mesmos envolvamse com a pátria. E, criticando os maus legisladores que buscam submeter os povos à lei por meio da coerção e de punições, pergunta: "como alcançar seus corações?" (ROUSSEAU, 1964. p. 955). Longe de um demiurgo solitário, o legislador pode ser compreendido, antes, como um sensível conselheiro, pois - adverte Rousseau:

Aquele, pois, que redige as leis, não tem nem deve ter qualquer direito legislativo. O próprio povo não poderia, se o desejasse, despojar-se desse direito incomunicável, porque, segundo o pacto fundamental, só a vontade geral obriga os particulares e só podemos estar certos que uma vontade particular é conforme à vontade geral depois de submetê-la ao sufrágio livre do povo. Já o tinha dito, mas não é inútil repeti-lo" (ROUSSEAU, 1978. L. II, cap. 7, p. 58).

A insistência de Rousseau - absolutamente evidente na última frase - tem o propósito de impedir qualquer tentativa de alijar o povo de seu direito legislativo. Ainda que apenas alguns tenham condições de desempenhar a tarefa de aconselhar o povo, não lhes cabe qualquer primazia decisória, pois, afirmando que "o Estado de forma alguma subsiste pelas leis, mas sim pelo poder legislativo" (ROUSSEAU, 1978. L. III, cap. 11, p. 103), Rousseau destaca que a conservação do corpo coletivo depende fundamentalmente de ação deste corpo sobre si mesmo. Segue-se, 
portanto, que Rousseau atribui aos próprios cidadãos a tarefa de manter o corpo político, pois afirma "depender deles prolongar a vida do Estado pelo tempo que for possível” (ROUSSEAU, 1978. L. III, cap. 11, p. 102).

Tão somente o corpo do povo tem o poder de autodeterminar-se, seja para o bem, seja para o mal. Isso significa que cada um dos indivíduos membros do corpo coletivo - mesmo os mais simples do povo - não estão à mercê, posto que são cidadãos livres e iguais. Cabe, necessariamente, a cada um, na qualidade de parte do todo, determinar a si mesmo e a quem quer que seja, por meio da vontade geral. Tal exigência é coerente com o propósito dos homens naquele instante feliz que os arrancou para sempre da vida e independente e suficiente.

\section{O esforço de cada um}

A transformação do indivíduo em cidadão se processa por meio da integração de cada um com cada um dos demais e, ao mesmo tempo, da integração de cada um ao todo, a fim de que os indivíduos possam reconhecer a si mesmos e a todos demais como cidadãos responsáveis pela determinação do bem comum. Ainda que o legislador possa atuar de forma significativa para favorecer o processo de integração entre os homens que transforma cada um em membro do corpo coletivo, ninguém está isento da necessidade de buscar, por si mesmo, a realização do propósito comum.

A integração entre os cidadãos e com o corpo coletivo exige de cada um o esforço de alcançar algumas condições. Em primeiro lugar, importa a cada um melhor informar-se sobre o interesse comum esclarecendo o próprio entendimento e livrando-se de preconceitos. Embora seja quase óbvia a necessidade de informações claras e consistentes sobre qualquer objeto de deliberação, Rousseau observa que do fato de o povo ser suficientemente informado, não se segue ainda que sua deliberação seja exata. Segue-se apenas que está menos sujeita a ser ludibriada por outrem que queira fazer o seu interesse privado ser tomado como interesse público, mas não se segue que cada um não queira que o seu próprio interesse privado seja tomado como interesse público. Esta é uma razão para a radical oposição de Rousseau às associações ou sociedades parciais dentro do Estado. 
Assim, Rousseau agrega outras condições menos óbvias, mas igualmente fundamentais para a integração de cada um ao todo de modo que suas deliberações possam prolongar no tempo o propósito assumido naquele instante feliz em que se associaram. Tais condições são: que os cidadãos não tenham "qualquer comunicação entre si" e "que cada cidadão só opine de acordo consigo mesmo", e conclui que apenas então "resultaria sempre a vontade geral e a deliberação seria sempre boa" (ROUSSEAU, 1978. L. II, cap. 3, p. 47). Trata-se de considerar que estando os cidadãos suficientemente informados, cada um possa consultar a si mesmo, pois opinar de acordo com si mesmo significa considerar o bem comum a partir de si; significa dispensar mediações entre si e a coletividade; significa reconhecer-se como membro inseparável do corpo coletivo. Se essas condições decorrem de ser a vontade geral a vontade de cada indivíduo que reflete interiormente acerca de sua relação com seus concidadãos, ao reforçá-las Rousseau chama atenção ao esforço de cada um no processo de formação ou de transformação do indivíduo em cidadão.

O que está em questão aqui é fazer com que cada cidadão queira sempre o bem público como seu próprio interesse de modo imediato, dotando a vontade geral - que é a vontade de um corpo artificial - de uma espontaneidade que ela não tem. É neste sentido que segue a observação de Lourival Gomes Machado na nota 110 do Contrato Social publicado na Coleção Os Pensadores:

Mesmo no concerto tácito ou não preparado das opiniões particulares (necessariamente discordantes, posto que correspondem a impulsos individuais e a interesses privados), ela [a vontade geral] emerge natural e espontaneamente, pois que subjaz em todas as consciências capacitadas a exprimir-se. ${ }^{4}$

Destacando a necessidade de guiar os homens, Rousseau introduz figura do legislador, mas introduz também a ideia de que efetivamente o indivíduo não é, no instante do pacto, o que deveria ser. Esta diferença entre o que deveria ser e o que efetivamente é, ressalta a necessidade de

\footnotetext{
4 Grifo meu.
} 
não descuidar da importante e infindável tarefa formativa do cidadão desde o estabelecimento do pacto.

A transformação da natureza humana exigida pelo pacto pretende que cada um, por si mesmo, torne-se capaz de espontaneamente julgar em vista do bem público. Entretanto, é preciso ter claro que considerarse membro do corpo coletivo não é algo imediato, mas realiza-se, pouco a pouco, na exata proporção do envolvimento de cada um com aquilo que é comum. Exige esforço, que não é apenas daqueles de assumem a tarefa de instituir o corpo político, mas de cada um dos cidadãos. Sem este esforço compartilhado, não há igualdade nem liberdade, mas doutrinação e domínio. Finalmente, não devemos nos iludir querendo dar às obras humanas uma solidez que não lhe cabe. Rousseau adverte que "se queremos formar uma instituição duradoura, não pensemos, pois, em torná-la eterna”. (ROUSSEAU, 1978. L. III, cap. 11, p. 102). A tensão existente entre público e privado não pode ser extirpada e, na verdade, nem se trata disso.

\section{Referências}

DERATHÉ, R. Jean-Jacques Rousseau et la science politique de son temps. Paris: Vrin, 1979.

. L'homme selon Roussseau. In: . Pensée de Rousseau. Paris: Seuil, 1984.

FORTES, L. R. S. Rousseau: da teoria à prática. São Paulo: Ática, 1976.

FRANCISCO, M. de F. S. Autoridade e contrato pedagógico em Rousseau. In: MONTEAGUDO, R. Entre o direito e a história: a concepção do legislador em Rousseau. São Paulo: UNESP, 2006.

ROUSSEAU, Jean-Jacques. Considérations sur le Gouvernement de Pologne. Paris: Gallimard, 1964.

. Discour sur l'origine et les fondements de l'inegalité parmi les hommes. Paris: Gallimard, 1964. . Do Contrato Social. São Paulo: Abril Cultural, 1978. . Du Contract Social. Paris: Gallimard, 1964. 
. Du Contract Social - 1e version. Paris: Gallimard, 1964. . Emilio. São Paulo: Martins Fontes, 1999. . Projet de Constitution pour la Corse. Paris: Gallimard, 1964.

VARGAS, Yves. Introduction à l'Emile de Rousseau. Paris: PUF, 1995.

Data de registro: $17 / 10 / 2011$

Data de aceite: 19/10/2011 
